\title{
Effects of human blood red cells on the haemolytic capability of clinical isolates of Candida tropicalis
}

\author{
Marcia Cristina Furlaneto ${ }^{1 *}$, Daniel Favero ${ }^{1}$, Emanuele Julio Galvão França ${ }^{1}$ and Luciana Furlaneto-Maia ${ }^{2}$
}

\begin{abstract}
Background: Candida tropicalis is an increasingly important human pathogen associated with high mortality rates; however, little is known regarding the virulence properties of $C$. tropicalis, particularly the production of haemolytic factor. Although Candida spp may acquire iron from human blood red cells (RBCs) by producing a haemolytic factor that promotes cell lyses, at present there are no data regarding the effect of RBCs on the production of haemolytic molecules. The present study was undertaken to evaluate the role of human red blood cells on the production haemolytic factor by C. tropicalis; in addition, the transcription levels of a putative haemolysin-like protein gene $(H L P t)$ were also analysed.
\end{abstract}

Results: C. tropicalis isolates produced a haemolytic factor following growth in either the absence or presence of RBCs; however, distinct levels of haemolysis were observed, with $60 \%$ of the isolates exhibiting a significant increase in the production of haemolytic factor when grown in the presence of human RBCs. All isolates in which the putative HLPt gene was up-regulated in presence of human RBCs, ranging from 1.044 to 6.965-fold, also exhibited higher haemolytic activity following growth in the presence of RBCs compared to that observed in the absence of RBCs.

Conclusions: We propose that human RBCs may induce changes in the phenotypic expression of haemolytic factor and in transcriptional levels of the putative C. tropicalis HLPt gene in an isolate-dependent fashion.

Keywords: Haemolytic activity, Putative HLPt gene, Erythrocytes

\section{Background}

Non-Candida albicans Candida (NCAC) species are being increasingly reported as causative agents of severe systemic infections [1,2]. Among NCAC species, Candida tropicalis is one of the most commonly isolated species in tropical countries. For instance, according to recent epidemiological surveys, $C$. tropicalis is one of the main causal agents of candidemia in Latin America and Asia [3-7].

C. tropicalis is taxonomically close to Candida albicans, sharing several pathogenic traits [8]. The clinical importance of C. tropicalis infections is associated with high rates of morbidity and mortality that may exceed those reported for other Candida species, including $C$. albicans $[9,10]$. However, compared with C. albicans,

\footnotetext{
* Correspondence: furlaneto@uel.br

'Department of Microbiology, Paraná State University at Londrina, C.P. 6001, 86051990 Londrina, Brazil

Full list of author information is available at the end of the article
}

there are relatively few studies examining the virulence attributes of $C$. tropicalis.

Haemolytic activity is known to be a putative virulence factor contributing to disseminated candidal pathogenesis, particularly facilitating hyphal invasion in disseminated candidiasis $[11,12]$. The haemolytic factor of $C$. albicans is a mannoprotein, which has a cell-wall mannan sugar moiety structure [13]. The mannan fraction binds to the erythrocyte membrane, causing its rupture and allowing the release of haemoglobin which may be used as an iron source by the yeast [13-15].

The haemolytic capability of C. tropicalis has also been recognized as a putative trait related to its pathogenesis [16-20]. We have previously reported that a haemolytic factor produced by clinical isolates of $C$. tropicalis is released in the culture supernatant and that its production occurs in a glucose-dependent manner [19]. More recently, our group demonstrated that binding of the secreted haemolytic factor to lectin Concanavalin-A 
reduced the haemolytic activity of $C$. tropicalis to similar level as that observed for $C$. albicans, suggesting that the haemolytic factor secreted by $C$. tropicalis may be a mannoprotein and giving evidence for its involvement in haemolysis [20].

Currently, there are still few data concerning the molecular basis of haemolytic factor production by Candida species. Lachke et al. [21] have described a putative haemolysin gene in Candida glabrata termed HLP (haemolysin-like protein). Further, Luo et al. [22] demonstrated a positive correlation between the expression of HLP and haemolytic activity in C. glabrata.

In this study, we demonstrated for the first time that human red blood cells modulate the production of the haemolytic factor in C. tropicalis; furthermore, our data revealed a positive correlation between the mRNA expression of a putative haemolysin-like protein gene and the haemolytic activity in $C$. tropicalis isolates, which suggests a positive effect of RBCs on haemolysis.

\section{Methods \\ Candida tropicalis isolates}

Clinical isolates recovered from blood (136.06, 144.06, 189.06, 301.07), nail infections (151.06) and tracheal secretions (197.06, 201.06, 254.07, 344.07, 335.07) [23] were maintained as stock cultures from the Fungal Genetics Laboratory, The University of Londrina-Brazil on yeast extract-peptone-D-glucose (YPD) agar at $-20^{\circ} \mathrm{C}$ in glycerol.

\section{Preparation of red blood cells (RBCs)}

Human RBCs ( $\mathrm{A}^{+}$type) were centrifuged at $1080 \mathrm{~g}$ for $7 \mathrm{~min}$. The supernatant and buffy coats were removed, and the packed RBCs were resuspended in $\mathrm{Ca}^{2+}$ - and $\mathrm{Mg}^{2+}$-free phosphate-buffered saline (PBS-) and washed twice with the same PBS-buffer and centrifugation. The RBCs were then added to liquid RPMI 1640 medium without phenol red (Sigma Chemical Co., St. Louis, MO, USA) at a final concentration of $10^{8}$ cells $/ \mathrm{ml}$.

\section{Growth conditions}

Prior to cultivation in either the presence or absence of human RBCs, C. tropicalis isolates were grown overnight to stationary phase in $\mathrm{RPMI}$ at $37^{\circ} \mathrm{C}$ and $180 \mathrm{rpm}$. The procedure was repeated, after which cells were harvested by centrifugation (3000 g for $10 \mathrm{~min}$ ) and washed with sterile buffer (PBS-). The resultant suspensions were then inoculated with $10^{4}$ yeast $/ \mathrm{ml}$ in RPMI medium and in RPMI supplemented with human RBCs type $\mathrm{A}^{+}\left(10^{8}\right.$ cells $/ \mathrm{ml}$ ) followed by incubation at $37^{\circ} \mathrm{C}$ and $180 \mathrm{rpm}$ for $48 \mathrm{~h}$. Finally, cells were harvested by centrifugation (3000 $\mathrm{g}$ for $5 \mathrm{~min}$ ) and used for RNA extraction. The resulting culture supernatants were assayed for haemolytic activity.

\section{Haemolytic activity in the cell-free broth}

Haemolytic activity was determined as described previously [19]. Briefly, the culture supernatants were filtered $(0.22 \mu \mathrm{m}$ membranes, Millipore MILLEX GV) to ensure the complete cell removal and concentrated 2.5-times by freeze-drying followed by storage at $-20^{\circ} \mathrm{C}$. The cell-free culture supernatant and red blood cells (RBCs) suspended in RPMI medium $\left(1 \times 10^{8}\right.$ cells $\left./ \mathrm{ml}\right)$ were mixed at a $1: 1(\mathrm{v} / \mathrm{v})$ ratio, and incubated at $37^{\circ} \mathrm{C}$ for $15 \mathrm{~h}$. After the incubation, samples were centrifuged at $1000 \mathrm{~g}$ for $2 \mathrm{~min}$. Absorbance of the supernatant was determined at $405 \mathrm{~nm}$. Haemolysis was calculated according to the equation: Haemolysis (\%) $=100-[(\mathrm{Ap}-\mathrm{As}) /(\mathrm{Ap}-\mathrm{An}) \times$ 100)]; where Ap, As and An are the absorbance of the positive control, test sample and negative control, respectively. The positive control was the RBCs lysed with SDS $(0.6 \%)$ plus PBS- buffer at a $1: 1(\mathrm{v} / \mathrm{v})$ ratio, and the negative control was the human red blood cell suspension with RPMI plus PBS- buffer at a 1:1 (v/v) ratio. The results are given as the ratio between the haemolysis percentage of the test condition and control. The experiments were performed three times.

\section{A putative $C$. tropicalis haemolytic factor encoding gene}

A putative C. tropicalis orthologue gene to HLP, which encodes a haemolysin-like protein gene in C. glabrata, was searched using HLP specific primers [22] against C. tropicalis genomic DNA obtained as described previously [24]. The amplicon of a C. tropicalis putative HLPt (haemolysin-like protein) gene was generated in $50 \mu$ l of a reaction mixture containing $4 \mu \mathrm{l} \mathrm{DNA}(5 \mathrm{ng} / \mu \mathrm{l}), 612.5 \mu \mathrm{mol}$ of each dNTP (Invitrogen, Carlsbad, CA, USA), 40 pmol of each primer, and $2.5 \mathrm{U}$ of Taq polymerase (Invitrogen, Carlsbad, CA, USA). PCR reactions were performed at $94^{\circ} \mathrm{C}$ for $5 \mathrm{~min}$, followed by 35 cycles of $30 \mathrm{~s}$ at $94^{\circ} \mathrm{C}, 30 \mathrm{~s}$ at $56.6^{\circ} \mathrm{C}$ and $1 \mathrm{~min}$ at $72^{\circ} \mathrm{C}$, with an additional extension $\left(72^{\circ} \mathrm{C}, 10 \mathrm{~min}\right)$. All the PCR reactions were performed in a GeneAmp PCR system (Eppendorf, Mastercycler gradient). The amplicon obtained was sequenced using the DYEnamic ET dye Terminator Cycle Sequencing Kit (Amersham Pharmacia Biotech, Inc) on MegaBACE 1000. Characteristics of the obtained sequence such as homologies and the hydrophobicity profile were predicted by online tools. The alignment and comparison of the nucleotide and aminoacid sequences with sequences in the databases were performed using BLAST tools available on the NCBI (htpp://www.ncbi.nlm.nih.gov) and UniProt (http://www.uniprot.org) websites. Transmembrane region prediction was performed using TMpred (http:// www.ch.embnet.org/software/TMPRED_form.html).

\section{Reverse transcription-qPCR (RT-qPCR)}

HLPt primers were designed for RT-qPCR analysis using Gene Runner 3.05 software (http://www.generunner.com). 
$\beta$-actina $(A C T)$ was used as a reference housekeeping gene (Table 1). Primers had melting temperatures (Tm) between $58^{\circ} \mathrm{C}$ and $60^{\circ} \mathrm{C}$, and amplification products were 129 and 151 bp, respectively. The oligonucleotides did not show, when analysed by themselves or together, hairpin loops, dimmers, bulge loops or internal loops according to program analyses. Primer specificity was checked using BLAST analysis (Basic Local Alignment Search Tool, http://blast.ncbi.nlm.nih.gov) searches against the GenBank database. Standard gel electrophoresis using a $2 \%$ TBE gel was used to check for a single product of the expected size.

The assessment of differential expressions of the HLPt gene by $C$. tropicalis isolates was performed following growth in the absence of RBCs (RPMI medium) (control) and in RPMI supplemented with RBCs (test condition). After $48 \mathrm{~h}$ of culture, C. tropicalis cells were harvested, washed using distilled sterile water, suspended in Trizol $^{\oplus}$ (Invitrogen, Carlsbad, CA, USA) and frozen in liquid nitrogen. Total RNA was extracted with Trizol $^{\oplus}$, according to the manufacturer's instruction and suspended in $30 \mu \mathrm{l}$ of DEPC-treated water. Residual genomic DNA was eliminated by DNAse I (Invitrogen, Carlsbad, CA, USA). Purity of the extracted RNA was determined by the $260 / 280 \mathrm{~nm}$ ratio, and integrity was checked by electrophoresing on $1 \%$ agarose gel. RNA was stored at $-80^{\circ} \mathrm{C}$ until further use and quantified with a Nanodrop ND-1000 Spectrophotometer (NanoDrop Technologies Inc.). Reverse transcription was carried out using $500 \mathrm{ng}$ total RNA previously incubated at $64^{\circ} \mathrm{C}$ for $10 \mathrm{~min}$ and snap-cooled on ice for $2 \mathrm{~min}$ to denature. First-strand cDNA was synthesized by the addition of $\mathrm{MgCl}_{2}(4 \mathrm{mM}), 2 \mu \mathrm{l}$ of $10 \mathrm{x}$ PCR Buffer, dNTP mixture $(200 \mu \mathrm{M})$, Oligo $(\mathrm{dT})-18$ primer $(0.4 \mu \mathrm{M})$, RNase OUT (4 U) and reverse transcriptase RT M-ML V (0.5 U) (Invitrogen, Carlsbad, CA, USA). The mixture was incubated at $42^{\circ} \mathrm{C}$ for $60 \mathrm{~min}$. Synthesis reactions were performed in a GeneAmp ${ }^{\circ}$ PCR system (Eppendorf, Mastercycler gradient).

Real time PCR was carried out in a PTC-200 DNA Engine Cycler (MJ Research) with a Chromo4 ${ }^{\mathrm{TM}}$ Four-Color Real-Time System (Bio-Rad). The $20 \mu \mathrm{l}$ reaction was performed by using the Platinum ${ }^{\odot} \mathrm{SYBR}^{\oplus}$ Green qPCR Supermix-UDG (Invitrogen, Carlsbad, CA, USA), $20 \mu \mathrm{M}$ of each primer, and $6 \mu \mathrm{l}$ of a 1:20 cDNA dilution of each isolate in their respective growing conditions. The negative controls (with no DNA template) for each primer set were included in each run. Real-time PCR reactions were performed at $50^{\circ} \mathrm{C}$ for $2 \mathrm{~min}, 95^{\circ} \mathrm{C}$ for $5 \mathrm{~min}$, followed by 40 cycles of $30 \mathrm{~s}$ at $94^{\circ} \mathrm{C}, 30 \mathrm{~s}$ at $56,6^{\circ} \mathrm{C}$ and $1 \mathrm{~min}$ at $72^{\circ} \mathrm{C}$, with an additional extension $\left(72^{\circ} \mathrm{C}\right.$, $10 \mathrm{~min})$. Melting curve analysis was performed for each sample to assure that a single product was produced in each reaction.

RT-qPCR data were normalized with the constitutively expressed $\beta$-Actin gene $(A C T)$ [25]. Normalized data were then used to calculate the relative gene expression levels. An expression level corresponds to the expression of the HLPt gene in the presence of RBCs relative to its expression in the absence of RBCs.

Data from RT-qPCR reactions were previously analysed using MJ Opticon Monitor TM Analysis Software (MJ Research) for determination of $\mathrm{C}_{\mathrm{q}}$ (Quantification cycle) for each reaction and their respective efficiencies of amplification. The $\mathrm{C}_{\mathrm{q}}$ value for the HLPt and ACT genes was measured, and the expression level of $H L P$ for the different isolates was analysed using the efficiency adjusted normalization method calculated by the formula: Ratio $=\left(E_{\text {target }}\right)^{\Delta \mathrm{Cq} \text { target(Mean control-Mean sample) }}$, $\left(\mathrm{E}_{\text {ref }}\right)^{\Delta \mathrm{Cq} \text { ref(Mean control-Mean sample) }}[26]$, representing the $\mathrm{x}$-fold difference from the calibrator $(A C T)$. To determine the changes in the relative gene transcription level presented as fold changes, a mathematical model for relative quantification was used [27]. Three independent experiments (biological and technical replicates) were performed in each condition, including growth, RNA extraction and qRT-PCR.

\section{Statistical analysis}

SPSS 17.0 software (SPSS Inc.) was used in the statistical analyses of haemolytic activity. A Kruskal-Wallis test was used to evaluate the significant differences in haemolytic activity promoted by the isolates grown in each of the two growth conditions. The relative expression software tool REST® [26] was used to determine the relative expression of the HLPt gene in the different culture conditions evaluated and to test whether the expression differences were significant. Gene expression in the test condition was considered significantly different,

Table 1 Primer sequences employed in the analyses of HLPt-mRNA expression and respective amplicon sizes

\begin{tabular}{lllll}
\hline Gene & Orientation & Sequence $\left(\mathbf{5}^{\prime} \rightarrow \mathbf{3}^{\prime}\right)$ & Amplicon size & Reference \\
\hline HLPt* & FW & TAGTGGGGCAAGTAGTGGG & $151 \mathrm{pb}$ & This study \\
& RV & GGTGGTGATAGATGTAGCAG & Vandeputte et al. [25] \\
B-Actin & FW & AACCTCTTCTCAATCATCTGC & $129 \mathrm{pb}$ & \\
& RV & GCTTCCAAACCTAAATCGGC & & \\
\hline
\end{tabular}

*HLPt primers were designed based on the complete ORF of the putative C. tropicalis haemolysin-like protein gene sequence using Gene Runner 3.05 software. 
either by induction or repression, from the control when $\mathrm{p}<0.001$.

\section{Results}

\section{Effect of red blood cells on production of haemolytic} factor

Differences in the levels of haemolysis obtained from cell-free broth following growth in the absence and presence of human RBCs are illustrated in Figure 1. All isolates tested produced a haemolytic factor that promoted the release of haemoglobin from human RBCs. The relative haemolysis data, giving by the ratio of the haemolysis percentage obtained in cultures in the presence of human RBCs relative to that in the absence of RBCs (RPMI cultures), are shown in Table 2. For $60 \%$ of the isolates, human RBCs had a positive effect on haemolysis promotion $(\mathrm{p}<0.05)$ (Table 2). Among these isolates, for isolate 189.06 (lowest relative haemolysis), the percentages of haemolysis from cell-free culture supernatants obtained following growth in the presence of RBCs relative to haemolysis in the absence of RBCs were $2.73 \pm$ $0.1 / 2.57 \pm 0.06$; for isolate 254.07 (highest relative haemolysis), the percentages of haemolysis from cell-free culture supernatants obtained following growth in the presence of RBCs relative to haemolysis in the absence of RBCs were $3.83 \pm 0.31 / 1.71 \pm 0.34$.

For $40 \%$ of the isolates, no significant differences were observed in the haemolytic activity between cultures grown in the presence or absence of RBCs (Table 2). Among these isolates, for isolate 197.06 (lowest relative haemolysis), the percentages of haemolysis from cellfree culture supernatants obtained following growth in the presence of $\mathrm{RBCs}$ relative to haemolysis in the absence of $\mathrm{RBCs}$ were $1.63 \pm 0.2 / 1.74 \pm 0.08$; for isolate

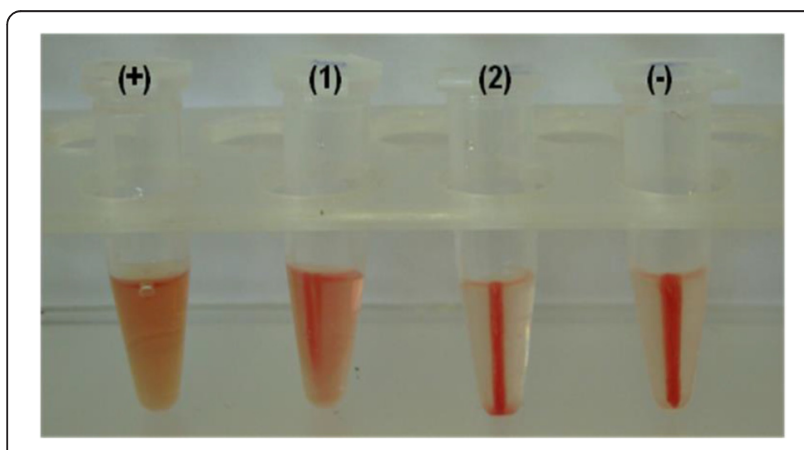

Figure 1 Representative photograph showing haemolysis promoted by the haemolytic factor produced by $C$. tropicalis. For haemolysis assays, cell-free culture supernatants and RBCs were mixed at a 1:1 (v/v) ratio following incubation at $37^{\circ} \mathrm{C}$ for $15 \mathrm{~h}$. (+) positive control (total lyses of RBCs in the presence of SDS), (1-2) haemolysis promoted by isolate 344.07 following growth in the presence and absence of RBCs, respectively, and (-) negative control (RBCs cells suspension with RPMI plus PBS buffer).
Table 2 Effect of human red blood cells (RBCs) on haemolysis promotion by clinical isolates of Candida tropicalis

\begin{tabular}{lll}
\hline Isolates & $\begin{array}{l}\text { Relative } \\
\text { haemolysis }\end{array}$ & $\begin{array}{l}\text { Effect of RBCs on } \\
\text { haemolysis promotion }\end{array}$ \\
\hline 136.06 & 1.25 & Positive $^{*}$ \\
144.06 & 2.12 & Positive $^{*}$ \\
189.06 & 1.06 & Positive $^{*}$ \\
151.06 & 1.88 & Positive $^{*}$ \\
254.07 & 2.24 & Positive $^{*}$ \\
344.07 & 1.67 & Positive $^{*}$ \\
301.07 & 0.94 & None \\
197.06 & 0.94 & None \\
201.06 & 0.95 & None \\
335.07 & 0.95 & None \\
\hline
\end{tabular}

${ }^{1}$ Relative haemolysis given by the ratio of haemolysis measured from cell-free culture supernatant obtained following growth in the presence of RBCs relative to haemolysis measured from culture supernatant obtained following growth in the absence of RBCs; *positive effect significant at $p<0.05$ by the KruskalWallis Test.

335.07 (highest relative haemolysis), the percentages of haemolysis from cell-free culture supernatants obtained following growth in the presence of $\mathrm{RBCs}$ relative to haemolysis in the absence of RBCs were $2.11 \pm 0.28$ / $2.21 \pm 0.06$. Additionally, to verify that RPMI medium did not promote human RBC haemolysis, a 2.5-times concentrated RPMI medium was tested by a haemolysis assay. No RBC lysis was observed (data not shown).

\section{A putative $C$. tropicalis haemolysin-like protein gene (HLPt)}

The employment of C. glabrata HLP gene primers against $C$. tropicalis genomic DNA resulted in an amplicon of approximately $400 \mathrm{bp}$ (data not shown). The BLASTN analysis (BLASTN algorithm against the GenBank database) revealed that the sequence of the amplicon exhibited high identity (98\%) to a C. tropicalis predicted protein mRNA (Candida tropicalis MYA-3404, GenBank: XM_002547122). The corresponding amino acid sequence of the obtained ORF had significant similarities to an uncharacterized threonine-rich GPI-anchored glycoprotein of the fission yeast Schizosaccharomyces pombe (EMBL Uniprot database: Q96WV6), indicating the presence of a possible domain that leads to a cell surface subcellular location. Furthermore, the in silico analysis inferred gene ontology of the HLPt gene product as a cellular component located on the external side of the cell wall. Moreover, the BLASTN analysis also revealed a high identity $(70 \%)$ to a C. albicans hypothetical protein SC5314 (CaO19.11047, GenBank: XM_709892), annotated as an ORF similar to the DAN4p cell wall mannoprotein of Saccharomyces cerevisiae (EMBL Uniprot database: P47179). Hydropathy plots show comparable 
peak profiles in the hydrophobicity index between the predicted protein of C. tropicalis and the C. albicans hypothetical protein (Figure 2), supporting the hypothesis that the C. tropicalis predicted protein may be correlated to a cell wall mannoprotein, though the achieved data do not allow its classification.
The complete ORF of the $C$. tropicalis sequence was used to design gene-specific primers for a $C$. tropicalis putative haemolysin-like protein $(H L P t)$ gene. The employment of these primers was successfully applied against $C$. tropicalis genomic DNA which resulted in an amplicon of 151 bp (data not shown) (Table 1).
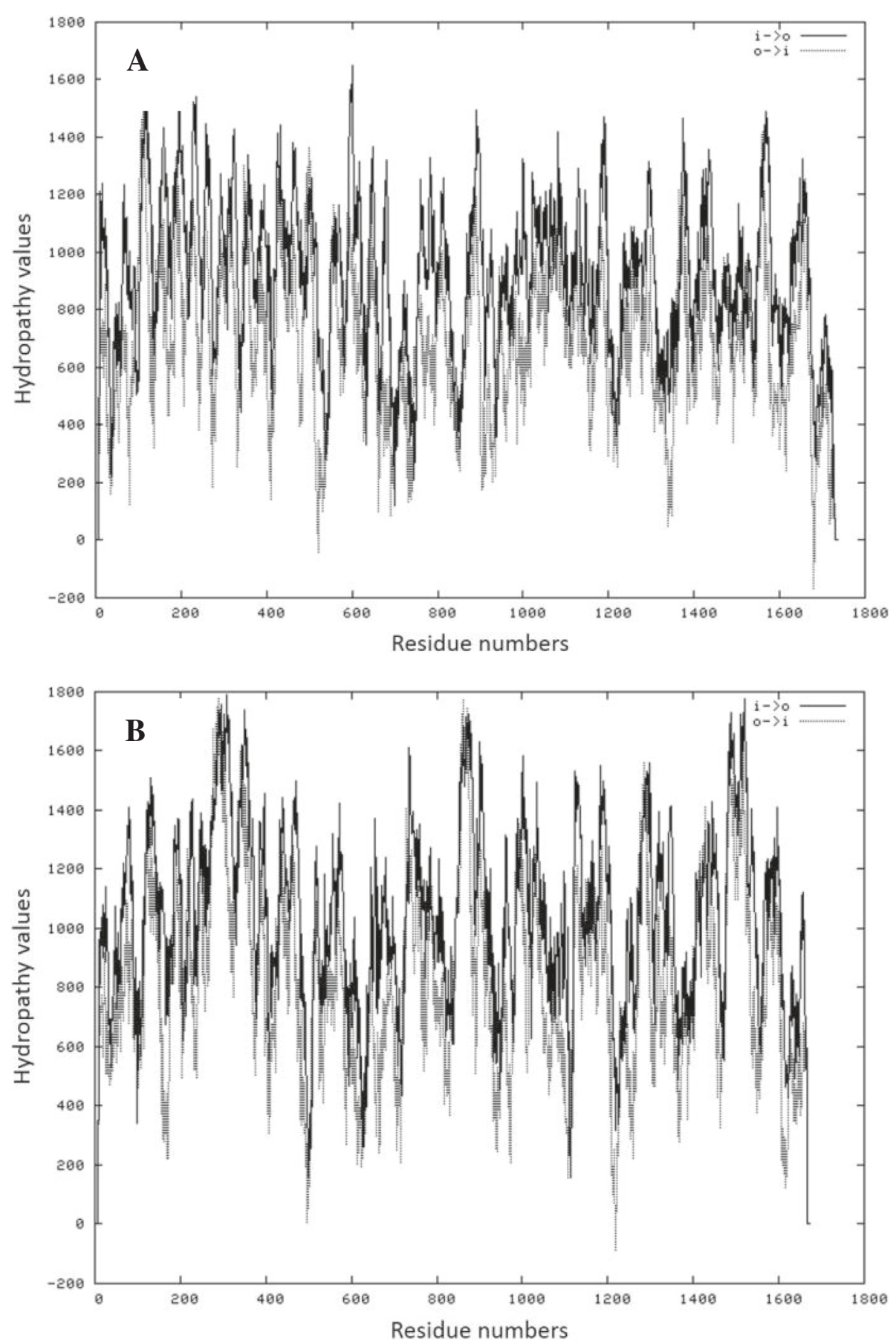

Figure 2 Hydrophobicity profile obtained by TMpred analyses. (A) TMpred obtained for C. tropicalis predicted protein (Candida tropicalis MYA-3404, GenBank: XM_002547122). (B) TMpred obtained for C. albicans hypothetical protein (CaO19.11047, GenBank: XM_709892) similar to a Saccharomyces cerevisiae cell wall mannoprotein (see Results section). 
Expression levels of a putative haemolysin-like protein gene Basic Local Alignment Search Tool (BLAST) analysis indicated that each primer pair employed in qPCR assays was specific for C. tropicalis HLPt and ACT genes and would not cross-react with sequences from other organisms (data not shown). Gel electrophoresis and melting curve analyses confirmed the presence of the expected qPCR products, and the absence of unwanted non-specific products, confirming that each primer pair was specific for its corresponding C. tropicalis gene. Non-inoculated media failed to show evidence of gene expression (data not shown). We found that the HLPt and ACT genes were expressed either in the presence or absence of RBCs at $48 \mathrm{~h}$.

Table 3 shows the relative expression of the HLPt gene in C. tropicalis. The mRNA levels of the HLPt gene were higher in culture medium supplemented with human RBCs than in RPMI medium alone for $60 \%$ of C. tropicalis isolates at statistically significant $(\mathrm{p}<0.001)$ levels, with an induction factor ranging from 1.044 to 6.965 fold. All isolates in which the HLPt gene was upregulated in the presence of human RBCs also exhibited higher haemolytic activity following growth in the presence of RBCs compared to that observed in the absence of RBCs (Table 2).

On the other hand, transcript levels were low for $40 \%$ of the isolates at statistically significant $(\mathrm{p}<0.001)$ levels with a repression factor of 1.338 to 4.429 -fold. These isolates exhibited the same extent of haemolytic activity in either the presence or absence of RBCs in culture medium.

\section{Discussion}

Despite the clinical importance of C. tropicalis, studies examining virulence attributes expressed by this species

\begin{tabular}{|c|c|c|}
\hline \multirow[b]{2}{*}{ Isolates } & \multicolumn{2}{|l|}{ Relative expression } \\
\hline & $\begin{array}{l}\text { Fold changes in mRNA expression } \\
\text { (RPMI + RBCs vs RPMI) }\end{array}$ & Regulation \\
\hline 136.06 & 1.244 & $U p^{*}$ \\
\hline 144.06 & 1.654 & Up* \\
\hline 189.06 & 1.044 & Up* \\
\hline 151.06 & 6.965 & Up* \\
\hline 254.07 & 2.032 & $U p^{*}$ \\
\hline 344.07 & 6.905 & Up* \\
\hline 301.07 & 4.429 & Down* \\
\hline 197.06 & 1.902 & Down* \\
\hline 201.06 & 3.82 & Down* \\
\hline 335.07 & 1.338 & Down* \\
\hline
\end{tabular}

*Significantly different by REST Software $(p<0.001)$. are scarce. In particular, studies regarding the production of molecules exhibiting haemolytic activity by Candida species are limited.

The ability of pathogenic microorganisms to acquire elemental iron has been shown to be essential to their survival within the mammalian host [28]. C. albicans may acquire iron from human RBCs by producing a haemolytic factor that consist of a cell wall mannoprotein with its sugar fraction identified as a cell-wall mannan; the mannan binds to $\mathrm{RBC}$ band 3 protein, causing $\mathrm{RBC}$ rupture and consequent release of haemoglobin, a source of iron for the yeast $[13,14]$.

Luo et al. [16] were the first to describe that C. tropicalis exhibits a haemolytic activity when grown on blood agar. We have first demonstrated that haemolytic factor is released in the culture supernatant of $C$. tropicalis isolates [19], and that it is produced by different isolates independent of their clinical origin [19,29]. Further, we demonstrated different abilities of haemolytic factor production among Candida species associated with bloodstream infections, where C. tropicalis exhibited higher haemolysis than C. albicans [20].

Concerning the cultures conditions under which $C$. tropicalis exhibits a haemolytic capability, it has been demonstrated that the production of haemolytic factor by this species occurs in a glucose-dependent manner $[19,30]$, and that it is not influenced by an increased atmosphere of carbon dioxide [19], differing from that observed in the prokaryote model.

Here, we evaluated for the first time the influence of human RBCs on the production of haemolytic factor by clinical isolates of $C$. tropicalis. In agreement with previous results $[19,20]$, the production of haemolytic molecules, following growth in RPMI medium, was a common trait of C. tropicalis isolates, e.g., all tested isolates produced haemolytic factor under this culture condition; however, growth in the presence of human RBCs resulted in higher haemolytic factor production for 6 out of 10 isolates tested compared to that obtained in medium where RBCs were absent. Our data revealed that human red blood cells seem to modulate the production of haemolytic factor and that it occurs in an isolate-dependent fashion. Although the haemolytic molecule produced by $C$. tropicalis has not yet been characterised at a biochemical level, we have recently suggested that it may be a mannoprotein, based on its affinity to Concanavalin A, similarly to that described for C. albicans [20]. Recently, it has been shown that $C$. albicans increases cell wall mannoproteins in response to blood [31]. According to these authors, the cell wall structure and composition, e.g., mannan chain length and complexity, are altered when C. albicans cells are grown in the presence of blood rather than standard laboratory growth media [31]. Moreover, it has been proposed that C. albicans upregulates cell wall mannan and/ 
or mannoprotein as a defense mechanism [32]. Our data raise the hypothesis that in $C$. tropicalis, the cell wall composition and/or architecture may be altered in response to the presence of red blood cells, in a similar fashion to that observed for $C$. albicans. Currently, the influence of growth conditions on the Candida spp cell wall remains largely unexplored, although the cell wall is a key effector of cell morphology and an active modulator of host immune defences.

In this study, we aimed to identify a putative gene encoding a haemolysin-like protein in C. tropicalis that was named HLPt in analogy to its C. glabrata orthologue $(H L P)$ [22]. To evaluate the transcription levels of HLPt we employed the quantitative real-time RT-PCR method. Our results revealed the presence of HLPt transcripts in all $C$. tropicalis isolates under both culture conditions tested, e.g., RPMI medium alone and RPMI supplemented with human red blood cells, suggesting that in C. tropicalis the HLPt gene may have an ubiquitous expression and that the HLPt gene product is a common characteristic in this species. To verify whether human RBCs modulate HLPt gene expression in C. tropicalis and to evaluate a possible correlation between the transcript levels and the profile of haemolysis promoted by different clinical isolates, the fold expression (expression level) of the HLPt gene was compared between the two culture conditions, e.g., absence and presence of RBCs. For the majority of isolates, the presence of RBCs upregulated HLPt transcription. For these isolates, we observed a positive correlation between HLPt induction and the production of haemolytic factor, revealed by the levels of haemolysis. On the other hand, some isolates showed RBC-repressed control of HLPt, although the observed haemolysis remained constant (Table 3). The reason for this absence of correlation between reduced expression of HLPt-mRNA and a reduction in haemolysis is unknown. One possible explanation may be related to cell density effects that may differed among isolates. Another possibility is that differences among isolates in the ability to promote the yeast-to-hypha transition may affect haemolysis levels. In another set of experiments carried out in our laboratory, we observed that $C$. tropicalis cells undertake a yeast-to-filamentous growth transition (hypha + pseudohypha) when cultured in the presence of RBCs and that this frequency is variable among isolates (unpublished data). According to Manns et al. [14], C. albicans hyphal cells were associated with higher haemolysis levels than blastoconidial cells.

As far as we know, this is the first study to analyse the differential expression of a putative haemolytic factor encoding gene in pathogenic Candida species. Future work must focus on the construction of C. tropicalis HLPt null mutants to evaluate environmental conditions that have effects on haemolysis.

\section{Conclusions}

We demonstrated that human red blood cells influence the production of haemolytic factor by clinical isolates of $C$. tropicalis. In addition, this study provides evidence that RBCs induce changes in the transcription levels of the putative $C$. tropicalis HLPt gene in an isolatedependent manner.

\section{Competing interests}

The authors declare that they have no competing interests.

\section{Authors' contributions}

MCF, LFM, EJGF and DF designed the experiments. DF conducted experiments and analysed the data. MCF and LFM analysed the data and wrote the manuscript. All authors read and approved the final manuscript.

\section{Acknowledgments}

This work was supported by the Conselho Nacional de Desenvolvimento Científico e Tecnológico (CNPq) - Brazil, Fundação Araucária/Governo do Paraná-Brazil and PROPPG/UEL-Brazil. Daniel Favero was a fellowship-holder of Coordenação de Aperfeiçoamento de Pessoal de Nível Superior (CAPES) -Brazil.

\section{Author details}

${ }^{1}$ Department of Microbiology, Paraná State University at Londrina, C.P. 6001,

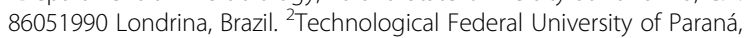
Paraná, Brazil.

Received: 22 September 2014 Accepted: 28 January 2015

Published online: 11 February 2015

\section{References}

1. Marra AR, Camargo LFA, Pignatari ACC, Brazilian SCOPE Study Group. Nosocomial bloodstream infections in Brazilian Hospitals: analysis of 2,563 cases from a prospective nationwide surveillance study. J Clin Microbiol. 2011;49:1866-71

2. Guinea J. Global trends in the distribution of Candida species causing candidemia. Clin Microbiol Infect. 2014;20:5-10.

3. Kothavade RJ, Kura MM, Valand AG, Panthaki MH. Candida tropicalis: its prevalence, pathogenicity and increasing resistence to fluconazole. J Med Microbiol. 2010;59:873-80.

4. Zhang XB, Yu SJ, Yu JX, Gong YL, Feng W, Sun FJ. Retrospective analysis of epidemiology and prognostic factors for candidemia at a hospital in China, 2000-2009. Jpn J Infect Dis. 2012;65:510-5.

5. Nucci M, Queiroz-Telles F, Alvarado-Matute T, Tiraboschi IR, Cortes J, Zurita J, et al. Epidemiology of candidemia in Latin America: a laboratory-based survey. PLoS One. 2013;8:e59373.

6. Chang TP, Ho MW, Yang YL, Lo PC, Lin OS, Wang AH, et al. Distribution and drug susceptibilities of Candida species causing candidemia from a medical center in Central Taiwan. J Infect Chem. 2013;19:1065-71.

7. Costa VG, Quesada RMB, Stipp-Abe AT, Furlaneto-Maia L, Furlaneto MC Nosocomial bloodstream Candida infections in a tertiary-care hospital in South Brazil: a 4-year survey. Mycopathologia. 2014;178:243-50.

8. Chai LYA, Denning DW, Warn P. Candida tropicalis in human disease. Crit Rev Microbiol. 2010;36:282-98.

9. Kontoyiannis DP, Vaziri I, Hanna HA, Boktour M, Thornby J, Hachem R, et al. Risk factors for Candida tropicalis fungemia in patients with cancer. Clin Infect Dis. 2001:33:1676-81.

10. Passos XS, Costa CR, Araujo CR, Nascimento ES, Souza LK, Fernandes OF, et al. Species distribution and antifungal susceptibility patterns of Candida spp.bloodstream isolates from a Brazilian tertiary care hospital. Mycopathologia. 2007:163:145-51

11. Odds FC. Candida and candidosis: a review and bibliography. London,UK: Bailliere Tindall; 1998

12. Pendrak ML, Yan SS, Roberts DD. Sensing the host environment: recognition of haemoglobin by the pathogenic yeast Candida albicans. Arch Biochem Bioph. 2004;426:148-56. 
13. Watanabe T, Takano M, Murakami M, Tanaka H, Matsuhisa A, Nakao N, et al. Characterization of a hemolytic factor from Candida albicans. Microbiology. 1999;145:689-94.

14. Manns JM, Mosser DM, Buckley HR. Production of a hemolytic factor by Candida albicans. Infect Immun. 1994;62:5154-6.

15. Watanabe T, Tanaka H, Nakao N, Mikami T, Matsumoto T. Hemoglobin is utilized by Candida albicans in the hyphal form but not yeast form. Biochem Biophys Res Commun. 1997:232:350-3.

16. Luo G, Samaranayake LP, Yau JY. Candida species exhibit differential in vitro hemolytic activities. J Clin Microbiol. 2001;39:2971-4

17. Deorukhkar SC, Saini S, Mathew S. Virulence factors contributing to pathogenicity of Candida tropicalis and its antifungal susceptibility profile. Int J Microbiol. 2014;2014:1-6 (ID 456878).

18. Negri M, Martins M, Henriques M, Svidzinski TIE, Azeredo J, Oliveira R. Examination of potential virulence factors of Candida tropicalis clinical isolates from hospitalized patients. Mycopathologia. 2010;169:175-82.

19. Favero D, França EJG, Furlaneto-Maia L, Quesada RMB, Furlaneto MC. Production of haemolytic factor by clinical isolates of Candida tropicalis. Mycoses. 2011;54:e816-20.

20. Favero D, Furlaneto-Maia L, França EJG, Góes HP, Furlaneto MC. Hemolytic factor production by clinical isolates of Candida species. Curr Microbiol. 2014:68:161-6.

21. Lachke SA, Srikantha T, Tsai LK, Daniels K, Soll DR. Phenotypic switching in Candida glabrata involves phase-specific regulation of the metallothionein gene MT-II and the newly discovered hemolysin gene HLP. Infect Immun. 2000;68:884-95.

22. Luo G, Samaranayake LP, Cheung BPK, Tang G. Reverse transcriptase polymerase chain reaction (RT-PCR) detection of HLP gene expression in Candida glabrata and its possible role in vitro haemolysin production. APMIS. 2004;112:283-90.

23. Furlaneto MC, Rota JF, Quesada RMB, Furlaneto-Maia L, Rodrigues R, Oda S, et al. Species distribution and in vitro fluconazole susceptibility of clinical Candida isolates in a Brazilian tertiary-care hospital over a 3-year period. Rev Soc Bras Med Trop. 2011:44:595-9.

24. Furlaneto-Maia L, Specian AF, Bizerra FC, Oliveira MT, Furlaneto MC. In vitro evaluation of putative virulence attributes of oral isolates of Candida spp. Obtained from elderly healthy individuals. Mycopathologia. 2008;166:209-17.

25. Vandeputte $P$, Larcher $G$, Bergès $T$, Renier $G$, Chabasse D, Bouchara JP. Mechanisms of azole resistance in a clinical isolate of Candida tropicalis. Antimicrob Agents Chem. 2005;49:4608-15.

26. Pfaffl MW. A new mathematical model for relative quantification real-time RT-PCR. Nucleic Acids Res. 2001;29:2002-7.

27. Pfaffl MW, Horgan GW, Dempfle L. Relative expression software tool (REST) for groupwise comparison and statistical analysis of relative results in real-time PCR. Nucleic Acids Res. 2002;30:e36

28. Bullen J. The significance of iron in infection. Rev Infect Dis. 1981;3:1127-38.

29. França EJG, Furlaneto-Maia L, Quesada RMB, Favero D, Oliveira MT, Furlaneto MC. Haemolytic and proteinase activities in clinical isolates of Candida parapsilosis and Candida tropicalis with reference to the isolation anatomic site. Mycoses. 2010;54:e44-51.

30. Malcok HK, Aktas E, Ayyildz A, Yigit N, Yazgi H. Hemolytic activities of the Candida species in liquid medium. Eurasian J Med. 2009:41:95-8.

31. Kruppa M, Greene RR, Noss I, Lowman DW, Williams DL. C. albicans increases cell wall mannoprotein, but not mannan, in response to blood, serum and cultivation at physiological temperature. Glycobiology. 2011;21:1173-80.

32. Klippel N, Cui S, Groebe L, Bilitewski U. Deletion of Candida albicans histidine kinase $\mathrm{CHK} 1$ improves recognition by phagocytes through an

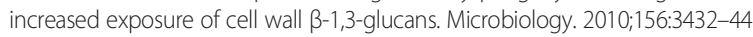

\section{Submit your next manuscript to BioMed Central and take full advantage of:}

- Convenient online submission

- Thorough peer review

- No space constraints or color figure charges

- Immediate publication on acceptance

- Inclusion in PubMed, CAS, Scopus and Google Scholar

- Research which is freely available for redistribution 